\title{
Role of Dexamethasone In Supraclavicular Brachial Plexus Block
}

\author{
Dr. Mijanur Rahaman Shaikh ${ }^{1}$, Dr. Saikat Majumdar ${ }^{2}$, Dr. Anjan Das ${ }^{3}$, \\ Dr. Tushar Kanti Saha ${ }^{4}$, Dr. Sambhu Nath Bandyopadhyay, \\ Dr. Dipankar Mukherjee ${ }^{6}$, Dr. Sanjay Mahawar ${ }^{7}$ \\ 1(RMO, Dept of Anaesthesiology, NRS Medical College, Kolkata); 2(Asst. Professor, Dept of Anaesthesiology, \\ NRS Medical College, Kolkata); 3(Asst. Professor, Dept of Anaesthesiology, CMSDH, Kolkata); 4(Asst. Prof., \\ Dept. of Community Mediicine, NRS Medical College, Kolkata); 5(Asst. Professor, Dept of Gynae \& Obs, \\ IPGMER, Kolkata); 6(Asso. Professor, Dept of Anaesthesiology, NRS Medical College, Kolkata); 7(Asst. \\ Professor, Dept of Anaesthesiology, NRS Medical College, Kolkata)
}

\begin{abstract}
Background- Supraclavicular brachial plexus block is a popular and widely employed regional nerve block technique.

Aims- To evaluate the effect of dexamethasone added to bupivacaine in supraclavicular brachial plexus block. Materials and Methods- 60 adult patients of either sex, aged 18 - 60 years,ASA physical status I or II ,posted for elective orthopedic surgeries of elbow, forearm and hand under supraclavicular brachial plexus block were enrolled in the study. Patients were randomly allocated to one of the two groups - group A and group B . Group $A(n=30)$-received $38 \mathrm{~mL} 0.25 \%$ bupivacaine and $2 \mathrm{~mL}$ dexamethasone $(8 \mathrm{mg})$. Group $B(n=30)$-received 38 $m L 0.25 \%$ bupivacaine and $2 \mathrm{~mL} 0.9 \%$ normal saline.

Statistics: Using software package SPSS16 for Windows statistical analysis done. Numerical variables compared by Independent samples t-test. Categorical variables compared between groups by Chi-square test. All analysis has been two tailed and $p<0.05$ has been taken to be statistically significant.

Results: No statistically significant difference between the groups in respect to patients' age, height, weight, duration of surgery (Independent samples t-test; $p>0.05$ ). Onset times of sensory and motor block were similar in the two groups. Duration of sensory $(1091.11 \pm 107.42 \mathrm{vs} 605.37 \pm 58.60)$ and motor blockade $(846.67 \pm$ 102.09 vs $544.07 \pm 55.40$ ) were significantly longer in the group A (dexamethasone group) than in the group $B$ (control group). less number of diclofenac sodium injection required in group A.

Conclusion: We conclude that addition of $8 \mathrm{mg}$ dexamethasone to bupivacaine $0.25 \%$ solution in supraclavicular brachial plexus block prolongs the duration of sensory and motor blockade, reduces the requirement of rescue analgesic in postoperative period but has no effect on the onset time of sensory and motor blockade.
\end{abstract}

Keywords: Dexamethasone, Bupivacaine, Supraclavicular Brachial Plexus Block

\section{Introduction}

Brachial plexus block is a popular and widely employed regional nerve block technique for perioperative anesthesia and analgesia for surgery of the upper extremity and supraclavicular approach is the easiest and most consistent method for surgery below the shoulder joint. Regional nerve block minimizes the stress response and using minimal anesthetic drugs is always beneficial for the patients with various cardiorespiratory comorbidities. ${ }^{1}$

Local anesthetics alone for Supraclavicular brachial plexus block provide good operative conditions but have shorter duration of postoperative analgesia. So various adjuvant like opioids, clonidine, neostigmine, midazolam, etc. were added to local anesthetics in brachial plexus block to achieve quick, dense and prolonged block, but the results are either inconclusive or associated with side effects. ${ }^{2}$

Steroids have powerful anti-inflammatory as well as analgesic property. They suppress inflammation through inhibition of phospholipase $\mathrm{A}_{2}$. Local application of methylprednisolone has been found to block transmission in nociceptive C-fibers but not in myelinated A-beta fibers. ${ }^{3}$ The effect was reversible, suggesting a direct membrane action of steroids. ${ }^{3}$ Corticosteroids also suppress ectopic neuronal discharge. ${ }^{4}$

Perineural injection of glucocorticoid along with local anesthetics is reported to influence the onset and duration of sensory and motor block. ${ }^{2,5,7}$

Dexamethasone is a very potent and highly selective glucocorticoid. Various studies have been done using dexamethasone $8 \mathrm{mg}$ as an adjuvant to local anaesthetics mixture in brachial plexus block resulting in variable effects on onset but prolonged duration of analgesia ${ }^{1,2,5,6,8-13}$ and motor block. ${ }^{1,9,10,13}$

In this context the present study has been undertaken to evaluate the effect of dexamethasone $8 \mathrm{mg}$, used as an adjuvant to $0.25 \%$ bupivacaine in supraclavicular brachial plexus block, on the onset time and duration of sensory as well as motor block. 


\section{Materials and Methods}

After obtaining permission from the Institutional Ethics Committee, patients attending pre-anesthesia check up clinic of R. G. Kar Medical College and Hospital for elective orthopedic surgeries of elbow, forearm and hand were enrolled in the study. Written informed consent was taken from all the willing participants after proper explanation of the study procedure and expected outcome in their own language.

Inclusion Criteria: Adult patients of either sex, aged $18-60$ years.ASA physical status I or II ,posted for elective orthopedic surgeries of elbow, forearm and hand under supraclavicular brachial plexus block.

Exclusion Criteria: ASA physical status III and more,Patients with history of peptic ulcer disease, diabetes mellitus, hepatic or renal failure, history of significant neurological, psychiatric, neuromuscular and cardiovascular disease.Patients receiving psychotropic drugs, chronic analgesic therapy,pregnancy,known hypersensitivity to study drugs were excluded from the study.

Patients were randomly allocated to one of the two groups - group A and group B .Brachial plexus block performed in supraclavicular route. Group A $(\mathrm{n}=30)$-received $38 \mathrm{~mL} 0.25 \%$ bupivacaine and $2 \mathrm{~mL}$ dexamethasone $(8 \mathrm{mg})$. Group B $(\mathrm{n}=30)$-received $38 \mathrm{~mL} 0.25 \%$ bupivacaine and $2 \mathrm{~mL} 0.9 \%$ normal saline.

Study Design: Prospective, randomized, double blinded study.

Intensity of pain assessed by 100 mm Visual Analogue Scale where o- 'no pain' and 100- 'worst pain imaginable'. Premedication: Tablet ranitidine $150 \mathrm{mg}$ was given at night for acid suppression. Tablet lorazepam $1 \mathrm{mg}$ was also given to ensure good night sleep. In the morning of operation tablet ranitidine $150 \mathrm{mg}$ and metoclopramide $10 \mathrm{mg}$ were given orally two hours before surgery.

Monitoring: After the patient's arrival at the operation theatre, multichannel monitor was attached for monitoring of ECG, heart rate, respiratory rate, noninvasive blood pressure (NIBP), $\left(\mathrm{SpO}_{2}\right)$. Baseline parameters were recorded.

Intravenous infusion of Ringers' lactate started and oxygen given @ 4-6 liters/minute via face mask. All patients received Inj. midazolam 0.03 to $0.04 \mathrm{mg} / \mathrm{kg}$ before procedure. Both patient and observer were blinded to the group allocation.

\section{Technique of Supraclavicular Brachial Plexus Block:}

After proper explanation of technique, block was performed in supine position with head rotated to the contralateral side and upper limb to be anesthetized was adducted and extended along the side toward the ipsilateral knee as far as possible. Interscalene groove was indentified $\&$ landmark was confirmed by palpation of the subclavian artery where a mark was made approximately 1.5 to $2.0 \mathrm{~cm}$ posterior to the mid-clavicle point .The stimulation frequency was set at $1 \mathrm{~Hz}$ and the intensity of the stimulating current was initially set to deliver $2 \mathrm{~mA}$ and was then gradually decreased. The 22 -gauge $5 \mathrm{~cm}$, insulated, stimuplex A needle. The position of the needle was considered to be acceptable when an output current $<0.5 \mathrm{~mA}$ still elicited a slight distal motor response in forearm and hand.

On negative aspiration for blood, a total volume of $40 \mathrm{ml}$ solution ( $38 \mathrm{ml} 0.25 \%$ bupivacaine $+2 \mathrm{ml}$ dexamethasone or normal saline) was injected slowly.The intercostobrachial nerve (T2) was blocked with $5 \mathrm{~mL}$ of $2 \%$ lignocaine with 1:200000 adrenaline to avoid tourniquet pain.

Assessment of Sensory and Motor Blockade: Sensory and motor blockade of radial, median, musculocutaneous, medial cutaneous nerve of arm and forearm, and ulnar nerves (C5-T1 dermatomes) were assessed every 2 minute after completion of injection till 30 minutes and then every 30 min after the end of surgery till first $12 \mathrm{hrs}$, thereafter hourly until the block had completely worn off. Sensory blockade of each nerve was assessed by pinprick and evaluated using a 3-point scale: $2=$ normal sensation, $1=$ loss of sensation to pinprick, and $0=$ loss of sensation to light touch. Motor block was tested by thumb abduction and wrist extension (radial nerve), thumb adduction and ulnar deviation of the hand (ulnar nerve), flexion of the elbow in supination (musculocutaneous), thumb opposition and wrist flexion (median nerve) and was measured using a 3point scale where $2=$ normal movement, $1=$ paresis, and $0=$ absent movement. Onset time of sensory block was defined as the time interval between the end of local anesthetic injection and loss of sensation to pinprick in all of the nerve distributions. Onset time of motor blockade was defined as the time interval between the end of local anesthetic injection and paresis (motor score $=1$ ) in all of the nerve distributions.

The duration of sensory block was defined as the time interval between the onset of sensory block and the first postoperative pain. The duration of motor block was defined as the time interval between the onset of motor block and complete recovery of motor functions. 
After 30 minutes, if the block was considered to be adequate, surgery commenced.

Injection diclofenac sodium (rescue analgesic) $75 \mathrm{mg}$ was given intramuscularly when VAS $\geq 30 \mathrm{~mm}$. Number of injection diclofenac given to each patient during first 24 hours of postoperative period was recorded.

Statistics: After completion of the assessment, data were unblinded and entered into statistical software package SPSS16 for Windows. Data have been summarized by routine descriptive statistics. Numerical variables have been compared between groups by Independent samples t-test.

Categorical variables like ASA status, sex, postoperative analgesic requirement and adverse effects have been compared between groups by Chi-square test. All analysis has been two tailed and $p<0.05$ has been taken to be statistically significant.

\section{Results and Analysis:}

A total of 80 patients were assessed initially for eligibility from January 2010 to July 2011 for inclusion into the study, out of which 60 patients received study drugs after randomization. Twenty patients were not included in this study on account of patient's refusal, change in the plan of surgery or anesthesia. Six patients were considered dropouts after initial randomization and therefore not subjected to statistical analysis (unsuccessful brachial plexus block in 5 patients, data not retrieved completely in 1 patients). Therefore data of remaining 54 patients were assessed for final analysis.

Table-1 shows that there are no statistically significant difference between the groups in respect to patients' age, height, weight, duration of surgery (Independent samples t-test; $\mathrm{p}>0.05$ ). It also shows that there is no statistically significant difference between the groups in respect to sex and ASA status (Chi-square test; $p>0.05$ ). So both the groups were comparable in respect to demographic parameters and duration of surgery.

Table-2 shows that there is no statistically significant difference between the groups in respect to onset time of sensory block ( $\mathrm{p}$ value $=0.201$ ). It also shows that there is no statistically significant difference between the groups in respect to onset time of motor block ( $p$ value $=0.402$ ). So the onset times of sensory and motor block were similar in the two groups.

Table-3 shows that the duration of sensory and motor blockade were significantly longer in the group A (dexamethasone group) than in the group B (control group). The difference in block durations between the two groups is statistically highly significant $(\mathrm{p}$ value $<0.001)$.

Table-4 depicts the post-operative rescue analgesic requirement in both the groups. Patients in group A (dexamethasone group) required less number of diclofenac sodium injection than patients in group B (control group) in first 24 hours of postoperative period, and the difference is statistically highly significant ( $p$ value $<$ $0.001)$.

Table-5 depicts the incidence of Horner's syndrome in both the groups. There is no statistically significant difference between the two groups regarding incidence of Horner's syndrome ( $p$ value $=0.783$ ). There were no incidences of adverse effects like seizure, bradycardia, hypotension, and dysrhythmia in any of the group. None of the patients had signs or symptoms indicative of a clinically significant pneumothorax.

\section{Discussion}

Supraclavicular brachial plexus block is a popular and widely employed regional nerve block technique for perioperative anesthesia and analgesia for surgery of the upper extremity. Local anesthetics alone for supraclavicular brachial plexus block provide good operative conditions but have shorter duration of postoperative analgesia. So various drugs like opioids, clonidine, neostigmine, Midazolam, etc. were used as adjuvant with local anesthetics in brachial plexus block to achieve quick, dense and prolonged block, but the results are either inconclusive or associated with side effects.

Glucocorticoids have powerful anti-inflammatory as well as analgesic property. Perineural injection of corticosteroid along with local anesthetics is reported to influence the onset and duration of sensory and motor block.

In the present randomized, double-blinded, clinical study we have evaluated the effect of $8 \mathrm{mg}$ dexamethasone used as an adjuvant to $38 \mathrm{~mL} 0.25 \%$ bupivacaine in supraclavicular brachial plexus block, on the onset time and duration of sensory and motor block as well as on the postoperative rescue analgesic (injection diclofenac sodium) requirement. 
In our study group A (dexamethasone group) received supraclavicular brachial plexus block with $38 \mathrm{~mL} 0.25 \%$ bupivacaine plus $2 \mathrm{ml}$ dexamethasone $(8 \mathrm{mg}$ ) and group B (control group) received supraclavicular brachial plexus block with $38 \mathrm{~mL} 0.25 \%$ bupivacaine plus $2 \mathrm{~mL} 0.9 \%$ normal saline.

The groups were comparable in respect to demographic parameters and duration of surgery.

The onset time of sensory block $(18.26 \pm 1.25 \mathrm{~min}$ in dexamethasone group versus $18.70 \pm 1.26 \mathrm{~min}$ in control group) was similar in the two groups ( $p$ value $=0.201)$. The onset time of motor block $(19.96 \pm 1.28 \mathrm{~min}$ in dexamethasone group versus $20.26 \pm 1.28 \mathrm{~min}$ in control group) was also similar in the two groups ( $\mathrm{p}$ value $=$ 0.402). These findings correlate with the studies of Movafegh A et al. ${ }^{9}$ and Parrington SJ et al. ${ }^{11}$

However, Golwala MP et $\mathbf{a l}^{2}$ and Yadav RK et al. ${ }^{8}$ in their studies, found significantly earlier onset of sensory and motor block in the local anesthetic plus dexamethasone group than in the control group. This discrepancy may be due to differences in study methodology such as use of varying methods of block assessment, higher dose of local anesthetic, and use of adjuncts like epinephrine.

In our study, the duration of sensory block $(1091.11 \pm 107.42 \mathrm{~min}$ in dexamethasone group versus $605.37 \pm 58.60 \mathrm{~min}$ in control group) was significantly longer in the dexamethasone group than in the control group ( $\mathrm{p}$ value $<0.001)$. The duration of motor block $(846.67 \pm 102.09 \mathrm{~min}$ in dexamethasone group versus $544.07 \pm 55.40 \mathrm{~min}$ in control group) was also significantly longer in the dexamethasone group than in the control group ( $p$ value $<0.001$ ). These findings lend support to the observations of various earlier studies by Movafegh A et al. ${ }^{9}$, Shrestha BR et al. ${ }^{1}$, Vieira PA et al. ${ }^{10}$ and Tandoc MN et al. ${ }^{13}$

In our study, mean duration of sensory block (analgesia) and motor block in the dexamethasone group were 18.18 hours $(1091.11 \mathrm{~min})$ and 14.1 hours $(846.67 \mathrm{~min})$ respectively. While mean duration of analgesia and motor block in the dexamethasone plus bupivacaine group were 25.2 hours and 39.2 hours respectively, in the study by Tandoc MN et al. ${ }^{13}$ The median duration of sensory and motor block in the dexamethasone plus bupivacaine group were 24.28 hours and 22.9 hours respectively, in the study by Vieira PA et al ${ }^{\mathbf{1 0}}$ Longer duration of sensory and motor block found in these studies may be due to use of higher concentration $(0.5 \%)$ and dose of bupivacaine and use of adjuncts like epinephrine and clonidine (in the study of Vieira PA et al. ${ }^{10}$ ).

The mean onset time and duration of sensory block in the control group of our study are similar to the results of the study by Hickey R et al. ${ }^{14}$ and the mean onset time and duration of motor block in the control group of our study correlate with the study of Tawfic TA et al. ${ }^{15}$

In our study, patients of dexamethasone group required significantly less number of diclofenac sodium injection in first 24 hours of postoperative period than the patients of control group ( $p$ value $<0.001$ ). This finding correlates with the studies of Vieira PA et al ${ }^{10}$, and Tandoc MN et al ${ }^{13}$ Reduced requirement of rescue analgesic in the dexamethasone group during first 24 hours of postoperative period is because of prolonged duration of sensory block.

In the present study, incidence of Horner's syndrome (12 cases in dexamethasone group versus 11 cases in control group) was similar in the two groups ( $p$ value $=0.783)$. Overall incidence of Horner's syndrome $(42.6$ $\%$ ) in the present study is comparable to the studies by Hickey $R$ et al. ${ }^{14}$ and Yang $\mathrm{CW}$ et al. ${ }^{16}$

We have used $38 \mathrm{ml} 0.25 \%$ bupivacaine (total dose $=95 \mathrm{mg}$ ) because the maximum dose of bupivacaine is 2 $\mathrm{mg} / \mathrm{kg}$ and $30-50 \mathrm{~mL}$ volume of $0.25 \%-0.5 \%$ bupivacaine has been recommended for brachial plexus block in the text book. ${ }^{17}$

The $8 \mathrm{mg}$ dose of dexamethasone was chosen because it has been used previously for perineural injection and is within the dose range used clinically for postoperative nausea. ${ }^{12}$

The mechanism of action of dexamethasone in prolonging peripheral neural blockade is not clearly understood. The block effect may be due to its local action and not a systemic one. ${ }^{18}$ In brief, the prolongation of duration of sensory and motor blockade after perineural administration of dexamethasone may be secondary to its local action on nociceptive $\mathrm{C}$ fibers mediated via membrane associated glucocorticoid receptors ${ }^{3}$ and the upregulation of the function of potassium channels in excitable cells. ${ }^{19,20}$ The safety of dexamethasone use in a nerve sheath may raise some concerns. However, the use of dexamethasone at doses between 4 and $12 \mathrm{mg}$ via the intravenous, perineural, and epidural route is described in regional anesthesia and pain medicine text books. ${ }^{11}$ Reports of corticosteroid mediated neurotoxicity seem to be related to the vehicle polyethylene glycol and the preservative benzyl alcohol in steroid preparations as well as the presence of insoluble steroid particulate matter in the injectate. ${ }^{21}$ Dexamethasone sodium phosphate is a nonparticulate steroid and does not contain either polyethylene glycol or benzyl alcohol. ${ }^{21}$ In vivo and in vitro animal studies have demonstrated that locally applied corticosteroid have no long term effect on the structure, electrical properties, or function of the peripheral nerves ${ }^{22}$ and that the extrafascicular and intrafascicular injection of dexamethasone in a rat sciatic nerve experimental model caused no or minimal peripheral nerve damage, respectively when compared with other steroids such as hydrocortisone or triamcinolone. ${ }^{23}$

Finally the frequency of unsuccessful blockade ( $8.3 \%$ ) encountered in the present study is comparable to previous studies using nerve stimulator guided approaches to supraclavicular brachial plexus blockade. ${ }^{24,25}$ 


\section{Conclusion}

We conclude that addition of $8 \mathrm{mg}$ dexamethasone to bupivacaine $0.25 \%$ solution in supraclavicular brachial plexus block prolongs the duration of sensory and motor blockade, reduces the requirement of rescue analgesic in postoperative period but has no effect on the onset time of sensory and motor blockade.

\section{References}

[1]. Shrestha BR, Maharjan SK, Shrestha S, Gautam B, Thapa C, Thapa PB et al. Comparative study between tramadol and dexamethasone as an admixture to bupivacaine in supraclavicular brachial plexus block. J Nepal Med Assoc 2007; 46(168):158-64.

[2]. Golwala MP, Swadia VN, Dhimar AA, Sridhar NV. Pain relief by dexamethasone as an adjuvant to local anaesthetics in supraclavicular brachial plexus block. J Anaesth Clin Pharmacol 2009; 25(3):285- 8.

[3]. Johansson A, Hao J, Sjölund B. Local corticosteroid application blocks transmission in normal nociceptive C-fibres. Acta Anaesthesiol Scand 1990; 34:335-8.

[4]. Devor MD, Gorvin-Lippmann R, Raber P. Corticosteroids suppress ectopic neural discharge originating in experimental neuromas. Pain 1985; 22:127-37.

[5]. Castillo J, Curley J, Hotz J, Uezono M, Tigner J, Chasin M, et al. Glucocorticoids prolong rat sciatic nerve blockade in vivo from bupivacaine microspheres. Anesthesiology 1996; 85:1157-66.

[6]. Shrestha BR, Maharjan SK, Tabedar S. Supraclavicular brachial plexus block with and without dexamethasone - A comparative study. Kathmandu University Medical Journal 2003; 1:158- 60.

[7]. Stan T, Goodman EJ, Bravo-Fernandez C, Holbrook CR. Adding methylprednisolone to local anesthetic increases the duration of axillary block. Reg Anesth Pain Med 2004; 29(4):380-1.

[8]. Yadav RK, Sah BP, Kumar P, Singh SN. Effectiveness of addition of neostigmine or dexamethasone to local anaesthetic in providing perioperative analgesia for brachial plexus block: A prospective, randomized, double blinded, controlled study. Kathmandu University Medical Journal 2008; 6(23):302-9.

[9]. Movafegh A, Razazian M, Hajimaohamadi F, Meysamie A. Dexamethasone added to lidocaine prolongs axillary brachial plexus blockade. Anesth Analg 2006; 102:263-7.

[10]. Vieira PA, Pulai I, Tsao GC, Manikantan P, Keller B, Connelly NR. Dexamethasone with bupivacaine increases duration of analgesia in ultrasound-guided interscalene brachial plexus blockade. Eur J Anaesthesiol 2010; 27(3):285-8.

[11]. Parrington SJ, Donnell DO, Chan VWS, Shreves DB, Subramanyam R, Qu M, et al. Dexamethasone added to mepivacaine prolongs the duration of analgesia after supraclavicular brachial plexus blockade. Reg Anesth Pain Med 2010; 35:422-6.

[12]. Cummings KC, Napierkowski DE, Parra-Sanchez I, Kurz A, Dalton JE, Brems JJ, et al. Effect of dexamethasone on the duration of interscalene nerve blocks with ropivacaine or bupivacaine. Br J Anaesth 2011; 107(3):446-53.

[13]. Tandoc MN, Fan L, Kolesnikov S, Kruglov A, Nader ND. Adjuvant dexamethasone with bupivacaine prolongs the duration of interscalene block: a prospective randomized trial. J Anesth 2011; 25(5):704-709.

[14]. Hickey R, Garland TA, Ramamurthy S. Subclavian Perivascular Block: Influence of location of paresthesia. Anesth Analg 1989;68:767-71.

[15]. Tawfic TA, Hussein MA. A clinical and pharmacokinetic comparison of ropivacaine and bupivacaine for supraclavicular brachial plexus block in patients with chronic renal failure. Alexandria Journal of Anaesthesia and Intensive Care 2006; 9:23-8.

[16]. Yang CW, Kwon HU, Cho CK, Jung SM, Kang PS, Park ES, et al. A comparison of infraclavicular and supraclavicular approaches to the brachial plexus using neurostimulation. Korean J Anesthesiol 2010; 58: 260-266.

[17]. Berde CB, Strichartz GR. Local Anesthetics. In: Miller RD, Eriksson LI, Fleisher LA, Wiener-Kronish JP, Young WL, editors. Miller's Anesthesia. $7^{\text {th }}$ ed. Philadelphia: Churchill Livingstone Elsevier; 2010. p. 913-36.

[18]. Kopacz DJ, Lacouture PG, Wu D, Nandy P, Swanton R, Landau C. The dose response and effects of dexamethasone on bupivacaine microcapsules for intercostals blockade (T9 to T11) in healthy volunteers. Anesth Analg 2003; 96:576-82.

[19]. Takimoto K, Levitan ES. Glucocorticoid induction of Kv1.5 K+ channel gene expression in ventricle of rat heart. Circ Res 1994; 75:1006-13.

[20]. Attardi B, Takimoto K, Gealy R, Severns C, Levitan ES. Glucocorticoid induced up-regulation of a pituitary K+ channel mRNA in vitro and in vivo. Receptors Channels 1993; 1:287-93.

[21]. Benzon HT, Chew TL, McCarthy RJ, Benzon HA, Walega DR. Comparison of the particle sizes of different steroids and the effect of dilution: A review of the relative neurotoxicities of the steroids. Anesthesiology 2007; 106:331-8.

[22]. Johannsen A, Dahlin L, Kerns JM. Long term local corticosteroid application does not influence nerve transmission or structure. Acta Anaesthesiol Scand 1995; 39:364-9.

[23]. Mackinnon SE, Hudson AR, Gentili F, Kline DG, Hunter D. Peripheral nerve injection injury with steroid agents. Plast Reconstr Surg 1982; 69(3):482-90.

[24]. Franco CD, Vieira ZE. 1,001 subclavian perivascular brachial plexus blocks: success with a nerve stimulator. Reg Anesth Pain Med. 2000; 25(1):41-46.

[25]. Yasuda I, Hirano T, Ojima T, Ohira N, Kaneko T, Yamamuro M. Supraclavicular brachial plexus block using a nerve stimulator and an insulated needle. Br J Anaesth 1980; 52(4):409-411.

Table-1: Demographic parameters and duration of surgery

\begin{tabular}{|c|c|c|c|}
\hline Demographic data & Group A & Group B & P value \\
\hline Age (years) & $\mathbf{3 0 . 3 0} \pm \mathbf{1 0 . 3 7}$ & $\mathbf{3 1 . 0 4} \pm \mathbf{1 0 . 5 6}$ & $\mathbf{0 . 7 9 6}$ \\
\hline Sex- M/F & $17 / 10$ & $\mathbf{1 6 / 1 1}$ & $\mathbf{0 . 7 8 0}$ \\
\hline Height (cm) & $\mathbf{1 6 1 . 4 8 \pm 5 . 5 6}$ & $\mathbf{1 6 0 . 7 0} \pm 5.59$ & $\mathbf{0 . 6 1 1}$ \\
\hline Weight (kg) & $\mathbf{6 1 . 1 9} \pm \mathbf{5 . 1 2}$ & $\mathbf{6 0 . 6 7} \pm 5.41$ & $\mathbf{0 . 7 1 9}$ \\
\hline ASA status- I/II & $\mathbf{2 0} / 7$ & $\mathbf{1 8} / 9$ & $\mathbf{0 . 5 5 1}$ \\
\hline Height (cm) & $\mathbf{1 6 1 . 4 8} \pm \mathbf{5 . 5 6}$ & $\mathbf{1 6 0 . 7 0} \pm 5.59$ & $\mathbf{0 . 6 1 1}$ \\
\hline
\end{tabular}


Table-2: Onset time of sensory and motor block

\begin{tabular}{|c|c|c|c|}
\hline Onset time & Group A(mean \pm SD) & Group B(mean \pm SD) & P value \\
\hline $\begin{array}{c}\text { Onset time of sensory block } \\
\text { (minute) }\end{array}$ & $18.26 \pm 1.25$ & $18.70 \pm 1.26$ & 0.201 \\
\hline Onset time of motor block (minute) & $19.96 \pm 1.28$ & $20.26 \pm 1.28$ & 0.402 \\
\hline
\end{tabular}

Figure 1- Bar Diagram Showing Comparison of sensory and motor onset times

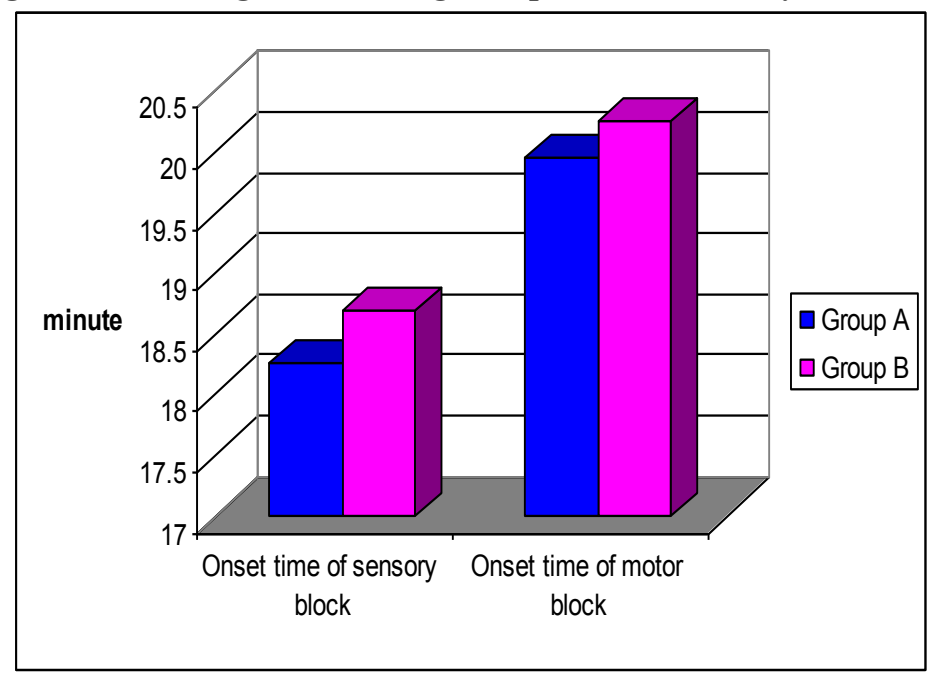

Table-3: Duration of sensory and motor block

\begin{tabular}{|c|c|c|c|}
\hline Duration of block & Group A(mean \pm SD) & Group B(mean \pm SD) & P value \\
\hline $\begin{array}{c}\text { Duration of sensory block } \\
\text { (minute) }\end{array}$ & $\mathbf{1 0 9 1 . 1 1 \pm 1 0 7 . 4 2}$ & $\mathbf{6 0 5 . 3 7} \pm \mathbf{5 8 . 6 0}$ & $\mathbf{0 . 0 0 0}$ \\
\hline $\begin{array}{c}\text { Duration of motor block } \\
\text { (minute) }\end{array}$ & $\mathbf{8 4 6 . 6 7 \pm 1 0 2 . 0 9}$ & $\mathbf{5 4 4 . 0 7 \pm 5 5 . 4 0}$ & $\mathbf{0 . 0 0 0}$ \\
\hline
\end{tabular}

Figure 2: Bar Diagram Showing Comparison of sensory and motor block durations

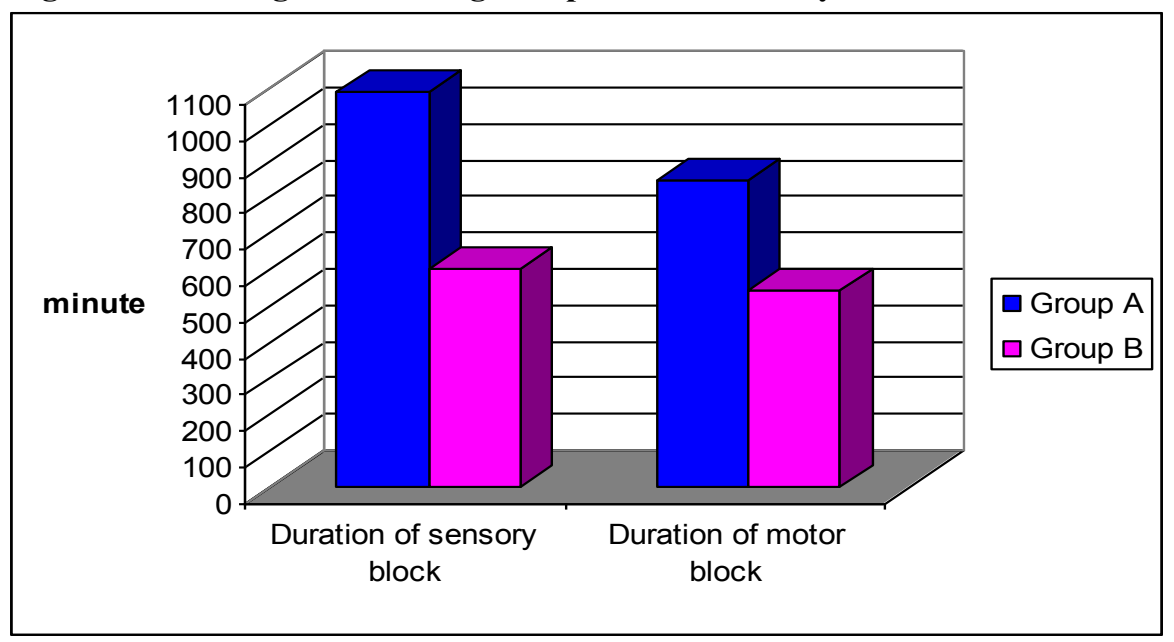

Table 4: Post-operative rescue analgesic requirement (Number of intramuscular diclofenac sodium injection) in first 24 hours

\begin{tabular}{|c|c|c|c|c|}
\hline \multirow{2}{*}{ Group } & \multicolumn{2}{|c|}{ No. of injection diclofenac required in first 24 hours of postoperative period } & p value \\
\cline { 2 - 5 } & 1 & 2 & 3 & 0 \\
\hline Group A & 25 & 2 & $\mathbf{2}$ & $\mathbf{3}$ \\
\hline Group B & 0 & 24 & 000 \\
\hline
\end{tabular}


Figure 3: Bar Diagram Showing Comparison of rescue analgesic requirement (number of diclofenac injection) in first $24 \mathrm{hrs}$ of postoperative period

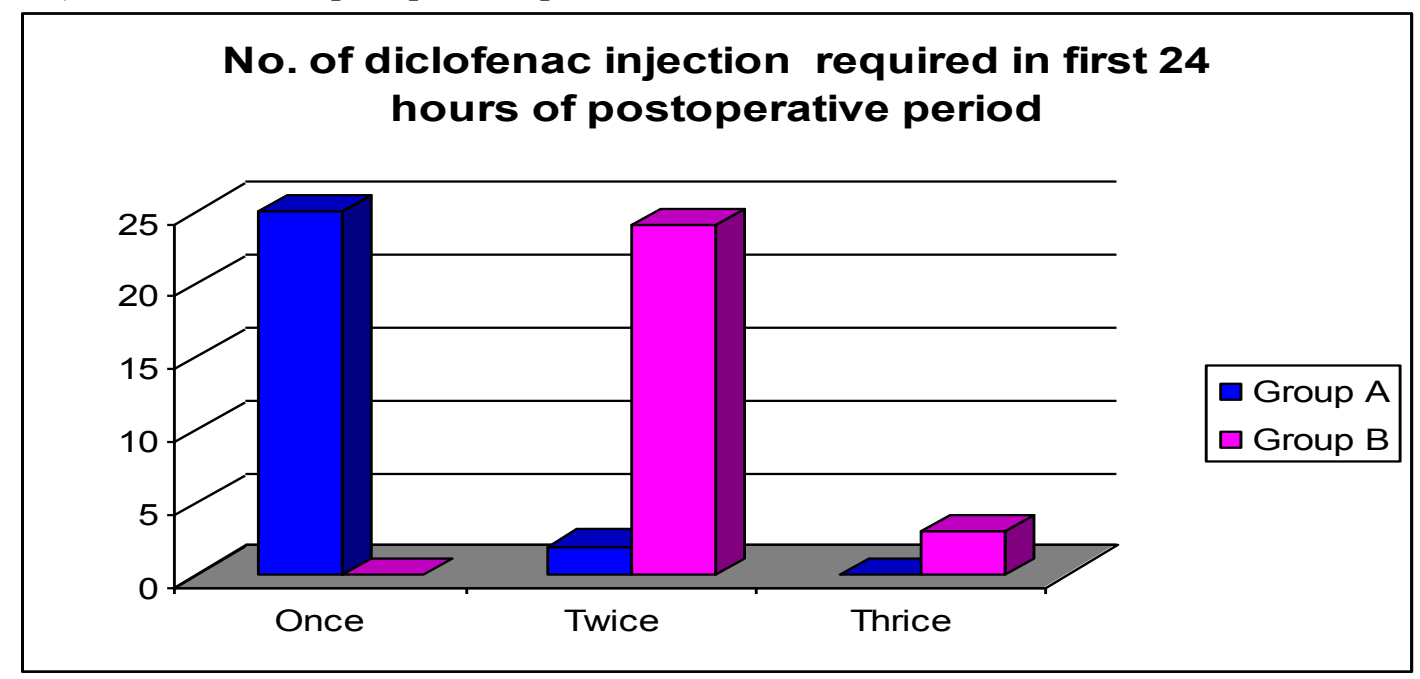

Table 5: Incidence of Horner's syndrome

\begin{tabular}{|c|c|c|c|}
\hline \multirow{2}{*}{ Group } & \multicolumn{2}{|c|}{ Horner's syndrome } & \multirow{2}{*}{ P value } \\
\cline { 2 - 3 } & No & Yes & \multirow{2}{*}{$\mathbf{0 . 7 8 3}$} \\
\hline Group A & 15 & 11 & \\
\hline Group B & 16 & 12 & \\
\hline
\end{tabular}

